\title{
Article \\ Area and Volume of Remaining Cement and Enamel after Removal and Polishing of Buccal or Lingual Multibracket Appliances
}

\author{
Alba Belanche Monterde ${ }^{1}$, Alberto Albaladejo Martínez ${ }^{1}$, Adrián Curto ${ }^{2}$, Jorge Alonso Pérez-Barquero ${ }^{3}$, \\ Clara Guinot-Barona ${ }^{4, *}$, Álvaro Zubizarreta-Macho ${ }^{5}$ (D) and Rosa María Calama González ${ }^{6}$ \\ 1 Department of Orthodontics, Faculty of Medicine and Dentistry, University of Salamanca, \\ 37008 Salamanca, Spain; belanche.alba@usal.es (A.B.M.); albertoalbaladejo@hotmail.com (A.A.M.) \\ 2 Department of Surgery, Faculty of Medicine and Dentistry, University of Salamanca, 37008 Salamanca, Spain; \\ adrian_odonto@usal.es \\ 3 Department of Stomatology, Faculty of Medicine and Dentistry, University of Valencia, 46010 Valencia, Spain; \\ jorgealonso86@gmail.com \\ 4 Department of Orthodontics, Faculty of Medicine and Health Sciences, Catholic University of Valencia, \\ 46001 Valencia, Spain \\ 5 Department of Endodontics, Faculty of Health Sciences, Alfonso X El Sabio University, 28691 Madrid, Spain; \\ amacho@uax.es \\ 6 Department of Orthodontics, Faculty of Health Sciences, Alfonso X El Sabio University, 28691 Madrid, Spain; \\ rosacago@uax.es \\ * Correspondence: clara.guinot@ucv.es
}

Citation: Belanche Monterde, A.; Albaladejo Martínez, A.; Curto, A.; Alonso Pérez-Barquero, J.;

Guinot-Barona, C.; Zubizarreta-Macho, Á.; Calama González, R.M. Area and Volume of Remaining Cement and Enamel after Removal and Polishing of Buccal or Lingual Multibracket Appliances. Appl. Sci. 2021, 11, 1719. https://doi.org/10.3390/app11041719

Received: 5 January 2021

Accepted: 12 February 2021

Published: 15 February 2021

Publisher's Note: MDPI stays neutra with regard to jurisdictional claims in published maps and institutional affiliations.

Copyright: (c) 2021 by the authors. Licensee MDPI, Basel, Switzerland. This article is an open access article distributed under the terms and conditions of the Creative Commons Attribution (CC BY) license (https:// creativecommons.org/licenses/by/ $4.0 /)$

\begin{abstract}
The aim of the present study was to compare the area and volume of remaining cement after lingual and buccal multibracket appliance debonding. Further, the area and volume of cement remaining and the area and volume of enamel were also analyzed using a morphometric digital measurement technique. Ten buccal and 10 lingual multibracket appliances were cemented in 20 extracted teeth embedded into an epoxy resin model simulating a dental arch. The models were scanned before bonding the lingual and buccal multibracket appliances, after debonding the lingual and buccal multibracket appliances, and after polishing the remaining cement. Afterwards, the standard tessellation language (STL) digital files were aligned, segmented, and realigned by using engineer morphometry software. A comparative analysis was performed using Student's $t$ test statistical analysis. Lingual appliances showed statistically significantly $(p<0.001)$ less area $\left(7.07 \pm 4.85 \mathrm{~mm}^{2}\right)$ and volume $\left(0.87 \pm 1.34 \mathrm{~mm}^{3}\right)$ of remaining cement than the area $\left(21.99 \pm 4.18 \mathrm{~mm}^{2}\right)$ and volume $(p=0.002)\left(3.48 \pm 0.96 \mathrm{~mm}^{3}\right)$ of buccal appliances. Moreover, lingual appliances showed statistically significantly $(p=0.001)$ less area $\left(4.48 \pm 3.08 \mathrm{~mm}^{2}\right)$ and volume $\left(0.13 \pm 0.15 \mathrm{~mm}^{3}\right)$ of remaining cement after polishing than the area $\left(12.22 \pm 5.98 \mathrm{~mm}^{2}\right)$ and volume $(p=0.004)\left(0.70 \pm 0.56 \mathrm{~mm}^{3}\right)$ of buccal appliances. Lingual multibracket appliance therapy leads to less area and volume of cement remaining after multibracket appliance debonding and less area and volume of cement remaining after cement polishing than buccal multibracket appliance therapy; however, the area and volume of enamel removed after cement polishing were similar between both lingual and buccal multibracket appliance therapies.
\end{abstract}

Keywords: orthodontics; remaining cement; enamel loss; debonding; morphometry

\section{Introduction}

Fixed multibracket appliances are a type of therapy widely used in orthodontics. Traditionally, fixed multibracket appliances were applied to buccal surfaces, but recently, lingual multibracket appliance therapy has emerged to meet aesthetic demands. In addition, lingual multibracket appliance therapy has shown the advantages of being invisible, having a lower incidence of white spot lesions, and having smaller interbracket distances [1]. Buccal 
multibracket appliance therapy has shown a higher risk of developing white spot lesions related to biofilm associated with poor hygiene. However, there are some strategies for their prevention, such as the application of acidulated phosphate fluoride, difluorosilane varnish, and high-concentration fluoride toothpastes [2,3]. Furthermore, lingual multibracket appliance therapy has shown some disadvantages, such as worse accessibility concerning the lingual/palatal surfaces, irregularities in the anatomy of lingual surfaces [4], and the worst dissolution of enamel prisms during enamel conditioning with etching agents [5]. Finally, the success of orthodontic treatment depends on obtaining ideal shear bond strength (SBS) between the fixed multibracket appliances and the enamel surfaces, which depends on the inner surface design of the fixed multibracket appliances, the type of mesh of the inner surface design of the fixed multibracket appliances, the size and shape of the fixed multibracket appliances, and the preconditioning of the enamel surfaces [6]. In addition, the development of the adhesion technique of orthodontic materials has improved the SBS values of fixed multibracket appliances [7], especially the acid etching technique, which decreases the amount of bond failures in fixed lingual multibracket appliance brackets [8]. However, after fixed multibracket appliance therapy debonding and polishing, it seems that there is an inevitable increase in enamel roughness $(\Delta S a)$ in both lingual and buccal multibracket appliance therapies [9], with significant differences in the degree of enamel damage regarding the type and material of the bur used [10], and with there being lower $\Delta S$ a values with composite and fiber glass burs [10]. Therefore, sandblasting procedures have been recommended in order to increase the SBS values of the preconditioned enamel surfaces, which not only increases the SBS values of fixed lingual multibracket appliances but also increases the amount of cement remnants over the lingual enamel surfaces [11]. Moreover, significant differences have been found between the SBS values of lingual multibracket appliance and buccal multibracket appliance therapies. This could influence the $\Delta \mathrm{Sa}$ and also the amount of cement remnants after multibracket appliance therapy debonding [5].

The aim of this study was to compare the area and volume of remaining cement after lingual and buccal multibracket appliance debonding, the area and volume of remaining cement after cement polishing, and the area and volume of enamel removed after cement polishing using a morphometric digital measurement technique, with a null hypothesis $\left(\mathrm{H}_{0}\right)$ stating that no difference exists between the area and volume of remaining cement after lingual and buccal multibracket appliance debonding, the area and volume of remaining cement after cement polishing, and the area and volume of enamel removed after cement polishing using a morphometric digital measurement technique.

\section{Materials and Methods}

\subsection{Study Design}

Twenty (20) upper teeth extracted for periodontal and orthodontic reasons, without tooth decay, restorations, or fractures, were selected in this study at the Dental Centre of Innovation and Advanced Specialties at Alfonso X El Sabio University (Madrid, Spain) between September and November 2020. A randomized controlled in vitro study was conducted in accordance with the principles defined in the German Ethics Committee's statement for the use of organic tissues in medical research (Zentrale Ethikkommission, 2003) and was authorized by the Ethical Committee of the Faculty of Health Sciences, University Alfonso X el Sabio (Madrid, Spain) in September 2020 (Process No. 09/2020). All patients provided informed consent to transfer the teeth for the study.

\subsection{Experimental Procedure}

The teeth were randomly (Epidat 4.1, Galicia, Spain) embedded into two experimental models of epoxy resin (Ref. 20-8130-128, EpoxiCure ${ }^{\circledR}$, Buehler, IL, USA) with 10 teeth each (central incisors, lateral incisors, canines, first and second premolars) following the manufacturer's recommendations, and the experimental models were randomly distributed to the following study groups. Group A: Buccal multibracket appliance therapy (MBT, 0.022, 
Pacific Orthodontics, Guadalajara, Spain) (Buccal) $(n=10)$; Group B: Lingual multibracket appliance therapy (Ref. 740-0430, Alias, Ormco, Glendora, CA, USA) (Lingual) $(n=10)$. The teeth were stored under humid conditions until the beginning of the study. Two experimental models were necessary in order to use an intact surface (buccal or palatal) to align the digital files. Afterwards, the experimental model was scanned with an intraoral scan (True Definition, 3M ESPE TM, Saint Paul, MN, USA) to obtain a standard tessellation language (STL) digital file (STL1), with a resolution of $54.68 \mathrm{pts} / \mathrm{mm}^{2}$ [12]. Then, buccal and lingual multibracket appliance therapies were bonded to the buccal and palatal enamel surface by a single operator using a three-step adhesive technique. An acid etching agent (Ortho Solo ${ }^{\mathrm{TM}}$, Ormco Corporation, CA, USA) was applied to the buccal and palatal enamel surface for $20 \mathrm{~s}$; afterwards, the acid etching (Ortho Solo ${ }^{\mathrm{TM}}$, Ormco Corporation, CA, USA) was removed under profuse washing and dried. Furthermore, a photopolymerized resin adhesive primer (Unitek Transbond ${ }^{\mathrm{TM}} \mathrm{XT}$, 3M ESPE ${ }^{\mathrm{TM}}$, Saint Paul, MN, USA) was gently applied using a microbrush (Plus slim; Microbrush International; Grafton; NSW, USA) on the previously etched buccal and palatal enamel surface and was photopolymerized (BluePhase G2 ${ }^{\mathrm{TM}}$, Ivoclar Vivadent, Schaan, Principado de Liechtenstein) for $20 \mathrm{~s}$. The fixed buccal (MBT, 0.022, Pacific Orthodontics, Guadalajara, Spain) and lingual (Ref. 740-0430, Alias, Ormco, Glendora, CA, USA) multibracket appliances were directly cemented from tooth 15 to 25 in the center of the buccal and palatal surface of the clinical crown with a photopolymerized composite resin cement (Transbond ${ }^{\mathrm{TM}}$ XT, 3M ESPE ${ }^{\mathrm{TM}}$, Saint Paul, MN, USA), which was photopolymerized (BluePhase G2 ${ }^{\mathrm{TM}}$, Ivoclar Vivadent, Schaan, Principado de Liechtenstein) for $20 \mathrm{~s}$. After that, the experimental models were subjected to digital impression through an intraoral scan (True Definition, 3M ESPE ${ }^{\mathrm{TM}}$, Saint Paul, MN, USA). Afterwards, the fixed buccal and lingual multibracket appliances were debonded using bracket remover Weingart pliers (Carl Martin, Solingen, Germany). Then, digital impressions (True Definition, 3M ESPE ${ }^{\mathrm{TM}}$, Saint Paul, MN, USA) were performed obtaining the STL2. Afterwards, the remaining cement of the fixed buccal and lingual multibracket appliances was removed from the buccal and palatal surfaces of the teeth using an adhesive remover bur (H379AGK, KOMET Dental, L Lemgo, Germany) mounted on a micromotor handpiece (INTRA MULTIflex L181M, KaVo, Biberach an der Riss, Germany) at 20,000 rpm with profuse irrigation until no cement remnants were visible to the clinician's eye. Finally, digital impressions (True Definition, 3M ESPE ${ }^{\mathrm{TM}}$, Saint Paul, MN, USA) of the experimental models were performed (STL3). The experimental procedures performed for both experimental models were performed by a unique operator.

\subsection{Alignment Procedure}

Once all the STL digital files were obtained (STL1-3), they were imported into the Geomagic Wrap's (3D Geomagic Capture Wrap, 3D Systems, Rock Hill, SC, USA) engineering software, which allowed us to create and analyze 3D images. Then, the STL digital files from 1 to 3 were aligned taking as reference the unmodified buccal or palatal surfaces, regarding the study group, to make an accurate alignment procedure of the digital files. Later, all STL digital files of teeth from 15 to 25 were digitally segmented and realigned in order to minimize the error rate in the alignment procedure (Figure 1a-d).

\subsection{Measurement Procedure}

All measurements were obtained from tooth 15 of each experimental model after a randomization procedure (Epidat 4.2, Galicia, Spain). The measurement procedures of the area and volume of remaining cement after buccal and lingual multibracket appliance debonding were performed by superimposing the STL1 and STL2 digital files after analyzing the boundary between the normals of the triangulated surface of the previously segmented and realigned STL1 and STL2 digital files (Figure 2). The spectrum was set to $\pm 100 \mu \mathrm{m}$ and the tolerance to $\pm 10 \mu \mathrm{m}$. 


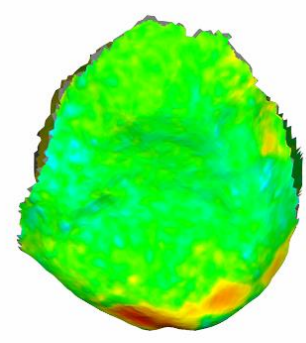

a)

c)

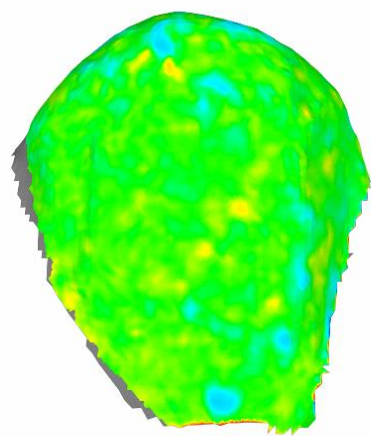

Figure 1. Palatal view of the alignment rate between the segmented and realigned the standard tessellation language 1 (STL1) and STL2 digital files (a) and between the segmented and realigned STL1 and STL3 digital files (b) of tooth 1.5 from the experimental model of the palatal multibracket appliance therapy. Buccal view of the alignment rate between the segmented and realigned STL1 and STL2 digital files (c) and between the segmented and realigned STL1 and STL3 digital files (d) of tooth 1.5 from the experimental model of the buccal multibracket appliance therapy. Warm colors represent a volume increase, cold colors represent a volume decrease, and green represents accurate alignment. Current values expressed in millimeters.

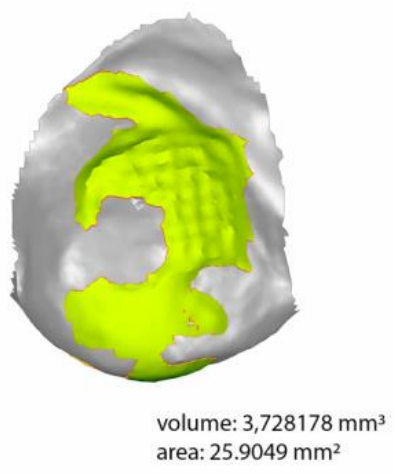

a) area: $25.9049 \mathrm{~mm}^{2}$

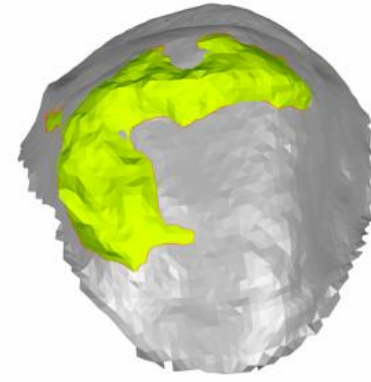

b) area: $12.0860 \mathrm{~mm}^{2}$

Figure 2. Buccal view of the measurement procedure of the area and volume of remaining cement after buccal multibracket appliance debonding (a). Palatal view of the measurement procedure of the area and volume of remaining cement after lingual multibracket appliance debonding (b). Boundary (red line) of the volume excess (yellow) between STL1 and STL2 digital files.

The measurement procedures of the area and volume of the remaining cement after cement polishing of the fixed buccal multibracket appliance therapy and the area and vol- 
ume of enamel removed after cement polishing of the fixed buccal multibracket appliance therapy were performed by comparing the STL1 and STL3 digital files (Figure 3). The spectrum was set to $\pm 100 \mu \mathrm{m}$ and the tolerance to $\pm 10 \mu \mathrm{m}$.

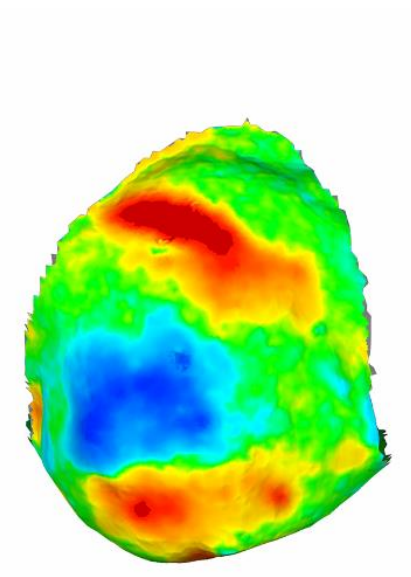

a)

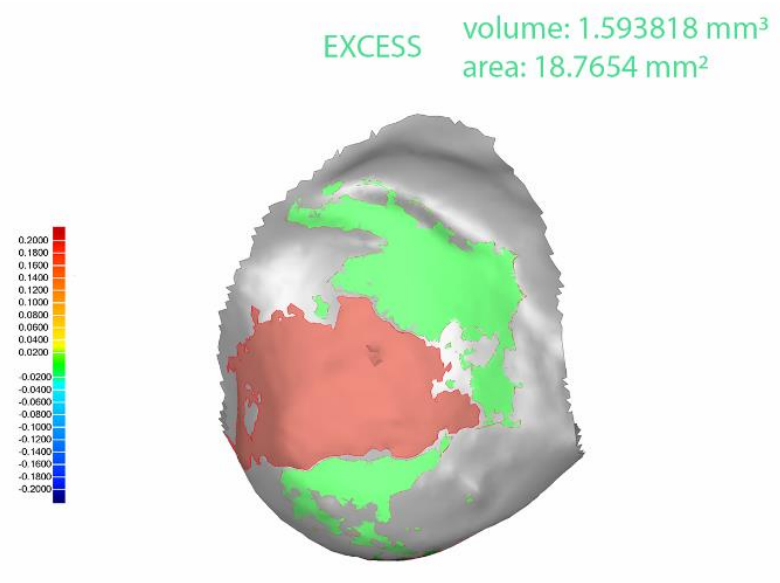

b) volume: $0.831800 \mathrm{~mm}^{3}$ area: $12.3492 \mathrm{~mm}^{2}$

Figure 3. Buccal view of segmented and realigned STL1 and STL3 digital files from tooth 1.5. Warm colors represent a volume increase (remaining cement after cement polishing), cold colors represent a volume decrease (enamel removed after cement polishing), and green represents accurate alignment (a). Boundary for the area and volume measurement of the remaining cement after cement polishing (green) and enamel removed after cement polishing (red) (b). Current values expressed in millimeters.

The measurement procedures of the area and volume of the remaining cement after cement polishing of the fixed lingual multibracket appliance therapy and the area and volume of enamel removed were performed by comparing the STL1 and STL3 digital files (Figure 4). The spectrum was set to $\pm 100 \mu \mathrm{m}$ and the tolerance to $\pm 10 \mu \mathrm{m}$.

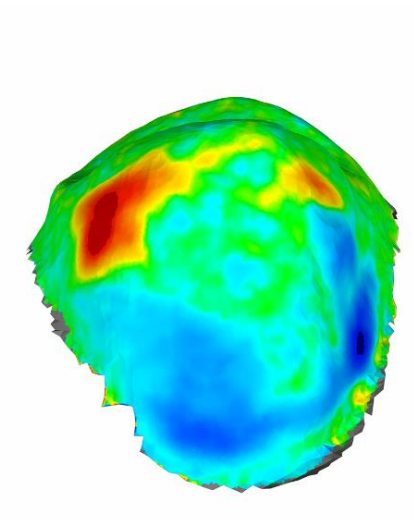

a)

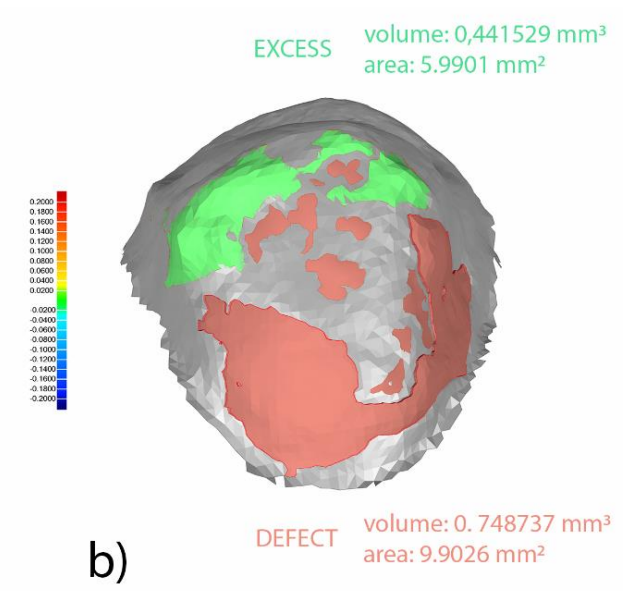

b)

Figure 4. Palatal view of segmented and realigned STL1 and STL3 digital files from tooth 1.5. Warm colors represent a volume increase (remaining cement after cement polishing), cold colors represent a volume decrease (enamel removed after cement polishing), and green represents accurate alignment (a). Boundary for the area and volume measurement of the remaining cement after cement polishing (green) and enamel removed after cement polishing (red) (b). Current values expressed in millimeters. 


\subsection{Statistical Tests}

The statistical analysis was performed using SAS 9.4 (SAS Institute Inc., Cary, NC, USA). Bivariate analysis was done using Student's $t$ test or Mann-Whitney nonparametric test for non-normal distributions. The assumption of normality was verified using the Shapiro-Wilk test. The statistical significance was set at $p<0.05$.

\section{Results}

The means and standard deviation (SD) values for the area $\left(\mathrm{mm}^{2}\right)$ and volume $\left(\mathrm{mm}^{3}\right)$ of remaining cement after lingual and buccal multibracket appliance debonding are displayed in Table 1 and Figure 5.

Table 1. Descriptive statistics of the area $\left(\mathrm{mm}^{2}\right)$ and volume $\left(\mathrm{mm}^{3}\right)$ of remaining cement after buccal and lingual multibracket appliance debonding.

\begin{tabular}{ccccccc}
\hline Study Group & Measure & $\boldsymbol{n}$ & Mean & SD & Median & Range \\
\hline \multirow{2}{*}{ Lingual } & Area & 10 & 7.07 & 4.85 & 5.34 & 12.95 \\
& Volume & 10 & 0.87 & 1.34 & 0.28 & 4.25 \\
\multirow{2}{*}{ Buccal } & Area & 10 & 21.99 & 4.18 & 22.60 & 13.72 \\
& Volume & 10 & 3.48 & 0.96 & 3.61 & 3.26 \\
\hline
\end{tabular}

SD: Standard deviation.

A

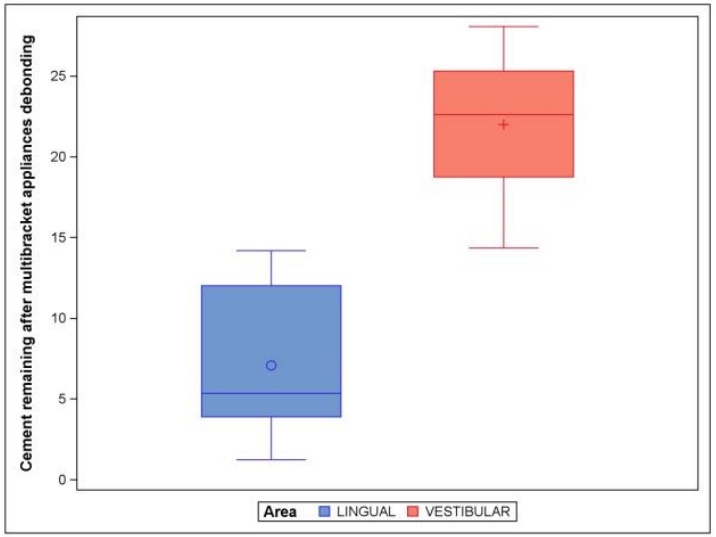

B

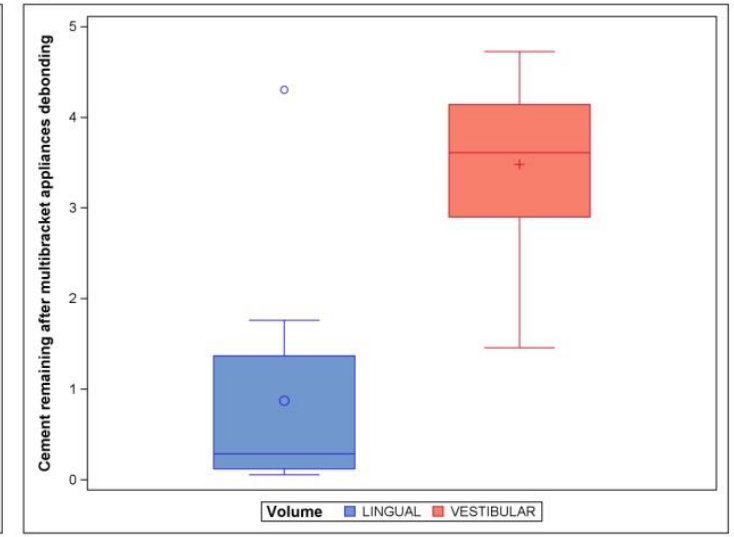

Figure 5. Boxplot of the area (A) and volume (B) of remaining cement after lingual and buccal multibracket appliance debonding. The horizontal line in each box represents the respective median value of the study groups. Blue represents lingual multibracket appliance and red represents buccal multibrackets appliance.

The paired $t$ test statistical analysis showed statistically significant differences $(p<0.001)$ between the area of remaining cement after lingual $\left(7.07 \pm 4.85 \mathrm{~mm}^{2}\right)$ and buccal $\left(21.99 \pm 4.18 \mathrm{~mm}^{2}\right)$ multibracket appliance debonding (Figure 5A). In addition, the paired $t$ test statistical analysis showed statistically significant differences $(p=0.002)$ between the volume of remaining cement after lingual $\left(0.87 \pm 1.34 \mathrm{~mm}^{3}\right)$ and buccal $\left(3.48 \pm 0.96 \mathrm{~mm}^{3}\right)$ multibracket appliance debonding (Figure 5B).

The means and SD values for the area $\left(\mathrm{mm}^{2}\right)$ and volume $\left(\mathrm{mm}^{3}\right)$ of remaining cement after cement polishing of the lingual and buccal multibracket appliance therapies are displayed in Table 2 and Figure 6. 
Table 2. Descriptive statistics of the area $\left(\mathrm{mm}^{2}\right)$ and volume $\left(\mathrm{mm}^{3}\right)$ of remaining cement after cement polishing of the lingual and buccal multibracket appliance therapies.

\begin{tabular}{ccccccc}
\hline Study Group & Measure & $\boldsymbol{n}$ & Mean & SD & Median & Range \\
\hline \multirow{2}{*}{ Lingual } & Area & 10 & 4.48 & 3.08 & 4.11 & 9.63 \\
& Volume & 10 & 0.13 & 0.15 & 0.07 & 0.43 \\
\multirow{2}{*}{ Buccal } & Area & 10 & 12.22 & 5.98 & 11.52 & 15.07 \\
& Volume & 10 & 0.70 & 0.56 & 0.46 & 1.37 \\
\hline
\end{tabular}

SD: Standard deviation.
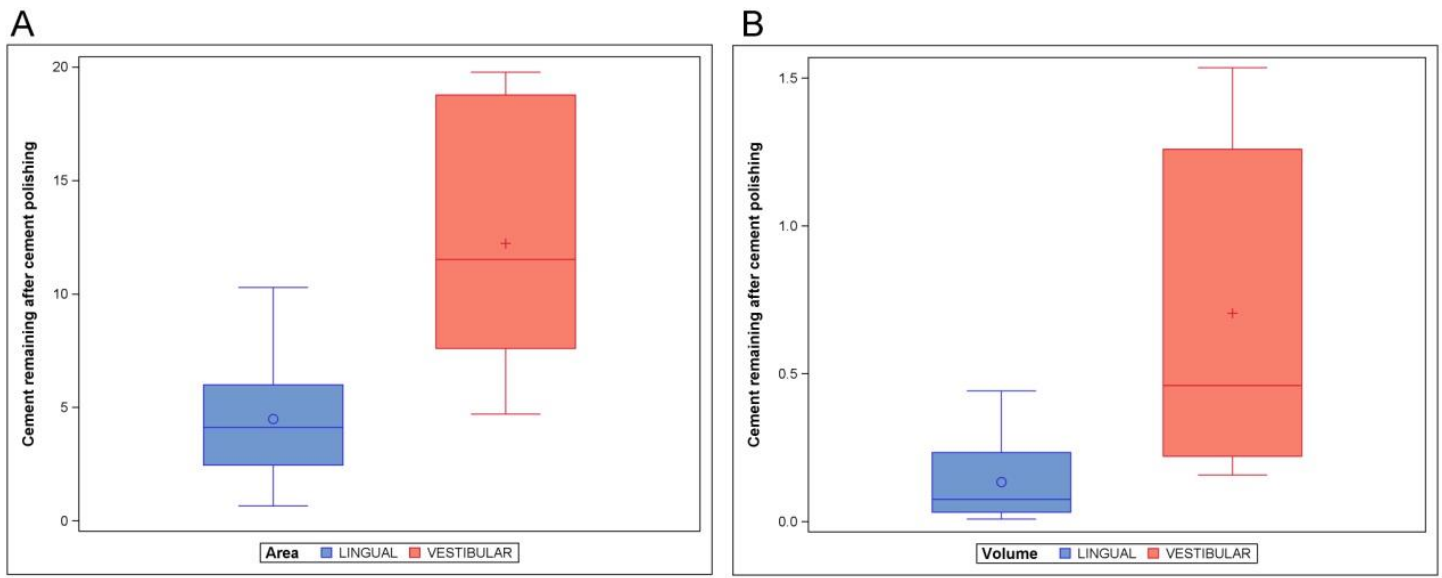

Figure 6. Boxplot of the area (A) and volume (B) of remaining cement after cement polishing of the lingual and buccal multibracket appliance therapies. The horizontal line in each box represents the respective median value of the study groups. Blue represents lingual multibracket appliance and red represents buccal multibrackets appliance.

The paired $t$ test statistical analysis showed statistically significant differences $(p=0.001)$ between the area of remaining cement after cement polishing of the lingual $\left(4.48 \pm 3.08 \mathrm{~mm}^{2}\right)$ and buccal $\left(12.22 \pm 5.98 \mathrm{~mm}^{2}\right)$ multibracket appliance therapies (Figure 6A). In addition, the paired $t$ test statistical analysis showed statistically significant differences $(p=0.004)$ between the volume of remaining cement after cement polishing of the lingual $\left(0.13 \pm 0.15 \mathrm{~mm}^{3}\right)$ and buccal $\left(0.70 \pm 0.56 \mathrm{~mm}^{3}\right)$ multibracket appliance therapies (Figure 6B).

The means and SD values for the area $\left(\mathrm{mm}^{2}\right)$ and volume $\left(\mathrm{mm}^{3}\right)$ of enamel removed after cement polishing of the lingual and buccal multibracket appliance therapies are displayed in Table 3 and Figure 7.

Table 3. Descriptive statistics of the area $\left(\mathrm{mm}^{2}\right)$ and volume $\left(\mathrm{mm}^{3}\right)$ of enamel removed after cement polishing of the lingual and buccal multibracket appliance therapies.

\begin{tabular}{ccccccc}
\hline Study Group & Measure & $\boldsymbol{n}$ & Mean & SD & Median & Range \\
\hline \multirow{2}{*}{ Lingual } & Area & 10 & 6.13 & 2.97 & 5.98 & 10.07 \\
& Volume & 10 & 0.49 & 0.42 & 0.32 & 1.46 \\
\multirow{2}{*}{ Buccal } & Area & 10 & 6.71 & 3.81 & 6.46 & 12.09 \\
& Volume & 10 & 0.33 & 0.26 & 0.27 & 0.79 \\
\hline
\end{tabular}

SD: Standard deviation.

The paired $t$ test statistical analysis did not show statistically significant differences $(p=0.709)$ between the area of enamel removed after cement polishing of the lingual $\left(6.13 \pm 2.97 \mathrm{~mm}^{2}\right)$ and buccal $\left(6.71 \pm 3.81 \mathrm{~mm}^{2}\right)$ multibracket appliance therapies (Figure 7A). In addition, the paired $t$ test statistical analysis did not show statistically significant differences $(p=0.307)$ between the volume of enamel removed after cement polishing of the lingual $\left(0.49 \pm 0.42 \mathrm{~mm}^{3}\right)$ and buccal $\left(0.33 \pm 0.26 \mathrm{~mm}^{3}\right)$ multibracket appliance therapies (Figure 7B). 
A

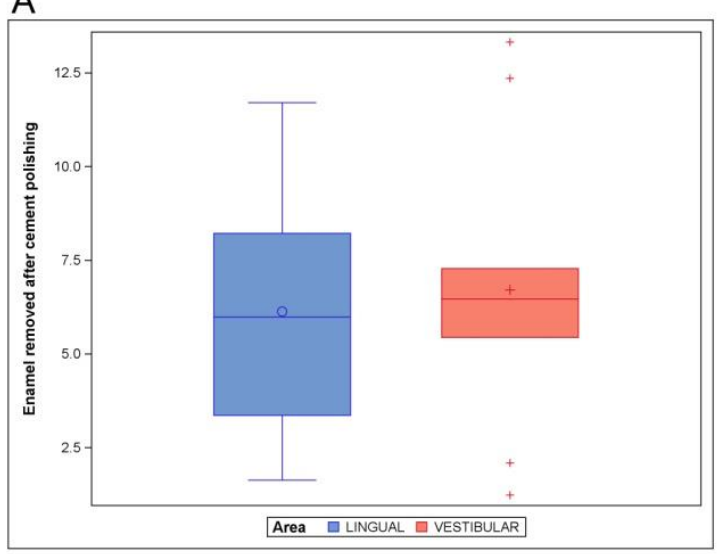

B

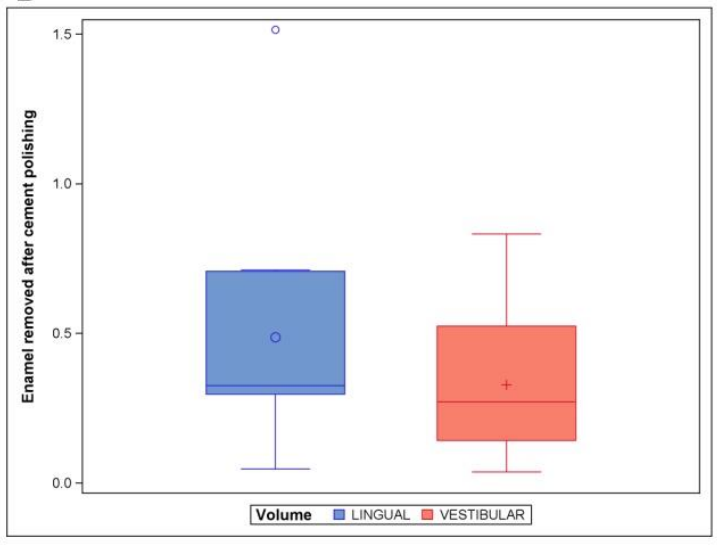

Figure 7. Boxplot of the area (A) and volume (B) of enamel removed after cement polishing of the lingual and buccal multibracket appliance therapies. The horizontal line in each box represents the respective median value of the study groups. Blue represents lingual multibracket appliance and red represents buccal multibrackets appliance.

\section{Discussion}

The results presented in this study reject the null hypothesis $\left(\mathrm{H}_{0}\right)$ stating that no difference exists between the area and volume of remaining cement after lingual and buccal multibracket appliance debonding and also between the area and volume of remaining cement after cement polishing of the lingual and buccal multibracket appliance therapies. However, the part of the null hypothesis $\left(\mathrm{H}_{0}\right)$ that states that no difference exists between the area and volume of enamel removed after cement polishing of the lingual and buccal multibracket appliance therapies using a morphometric digital measurement technique is accepted.

The results obtained in the present study showed statistically significant higher area and volume of remaining cement after buccal multibracket appliance debonding compared with lingual multibracket appliances, and statistically significant higher area and volume of remaining cement after cement polishing of the buccal multibracket appliance therapy compared with the lingual multibracket appliance therapy. However, no statistically significant differences were shown for the area or the volume of enamel removed after polishing the lingual and buccal remaining cement. Fixed lingual multibracket appliance therapies have been developed and used worldwide in order to avoid the demineralization process of the enamel surface around buccal multibracket appliances and also the formation of unaesthetic white spot lesions [9]. Moreover, fixed buccal multibracket appliance therapies have shown more than 4.8 times the risk of developing incipient tooth decay on buccal enamel surfaces compared with lingual/palatal enamel surfaces associated with fixed lingual multibracket appliance therapies [8]. However, the higher risk of incipient caries developing in the buccal enamel surfaces associated with the fixed buccal multibracket appliance therapies could be associated with a more reduced coverage of the buccal enamel surfaces by the mesh of the fixed buccal multibracket appliances in comparison with the fixed lingual multibracket appliance therapies [11]; however, other factors have been associated with incipient caries developing in the buccal enamel surfaces, such as biofilm formation conditioned by poor hygiene [13]. Nevertheless, the concept which concerns most researchers and clinicians is the SBS capability of multibracket appliance therapies to prevent unexpected multibracket appliance debondings and, hence, possible complications in orthodontic treatment. SBS has reported to be influenced by the design, shape, and size of the multibracket appliances and also by the enamel preconditioning [14]; the ideal SBS range is between 5.8 and $7.9 \mathrm{MPa}$ [15]. Furthermore, the nature of the orthodontic cement has also been reported to influence the SBS score of multibracket appliances; therefore, the same composite resin orthodontic cement was used in both lingual and buccal multibracket appliance therapies selected in this study. However, Tuncer et al. observed a higher SBS 
score associated with a fluoride-based cement in comparison with a conventional composite resin-based cement; therefore, the authors recommended fluoride-based cement for bonding lingual multibracket appliances due to its antimicrobial proprieties and the higher SBS score [16]. Moreover, the SBS could also vary depending on the characteristics of the adhesion surface of the multibracket appliances, if it has previous restorations, and their characteristics. Therefore, the adhesion surfaces should be analyzed before bonding to evaluate the necessity of previous conditioning [17]. Moreover, the acid etching of the enamel surfaces was analyzed in order to increase the SBS of multibracket appliances; however, no variations were shown on the lingual surfaces after preconditioning with laser and sandblasting [18]. On the other hand, a successful adhesion procedure between the enamel surface and the inner surface of multibracket appliances was achieved by etching with $37 \%$ orthophosphoric acid for $10 \mathrm{~s}$, increasing significantly the SBS in comparison with self-etching adhesion procedures [19]. Therefore, the SBS value could vary depending on the cement used. Valletta et al. obtained statistically significant differences in the SBS values of brackets cemented with glass-ionomer-modified cement compared with samples cemented with composite resin $(p=0.007)$ or light-activated composite resin $(p=0.001)$. However, they did not obtain significant differences in the SBS values between the composite resin study groups $(p=0.290)$. These results could be due to the fact that the glass-ionomer-modified group was etched with $10 \%$ acrylic acid, while in the composite groups, 37\% orthophosphoric acid was used [20]. Moreover, Vinagre et al. studied the differences in the SBS values between composite resin, a light-cured composite, and selfetched and concluded that the SBS value could vary over time until debonding in all the materials used [21]. Nevertheless, the contact area between the multibracket appliances and the enamel surface has not been found to influence the SBS of mesh-backed multibracket appliances; hence, the mesh area of multibracket appliances is smaller nowadays [22]. However, the mesh design of the multibracket appliances has been shown to significantly affect the SBS. Hudson et al. compared different mesh designs and reported that a single mesh crossing the base diagonally of multibracket appliances showed the highest SBS values [5]. In addition, Sharma-Sayal et al. showed that SBS values increased $24 \%$ after $24 \mathrm{~h}$ of bonding, and rebonded multibracket appliances also showed higher SBS values than multibracket appliances bonded for the first time [23]. In addition, Chumak et al. showed a statistically significantly higher SBS associated with premolars with lingual multibracket appliances adapted to the lingual enamel surface compared with a buccal multibracket appliance adapted to the buccal enamel surface, but lingual enamel surfaces were more susceptible to fracture and detachment than buccal enamel surfaces when vertical shear forces were applied [24]. However, Ziebura et al. did not report statistical bond failure between lingual and buccal multibracket appliances despite there being significant differences in the extent and design of both techniques [25]. Additionally, the adhesive remnant index (ARI) has been used to analyze the SBS and, hence, the remaining cement over the enamel surface after multibracket appliance debonding, and the calcium remnant index (CRI) has also been used to evaluate the cement remnants over multibracket appliance mesh after multibracket appliance debonding [8,9]. Brosh et al. reported a 15\% higher debonding strength in buccal multibracket appliances $(p<0.05)$ compared with lingual multibracket appliances. However, a significantly higher ARI score $(p<0.002)$ was found in the lingual surface of teeth submitted to lingual multibracket appliance therapy $(2.0 \pm 1.3)$ compared with the buccal surfaces of teeth submitted to buccal multibracket appliance therapy $(1.6 \pm 1.5)$. Additionally, a higher CRI score $(p<0.005)$ was also found in the mesh of lingual multibracket appliance therapy $(1.7 \pm 1.4)$ compared with the mesh of buccal multibracket appliance therapy $(1.1 \pm 1.5)$ [4]. These results do not agree with the findings obtained in the present study. The main reason for these discrepancies could be related to the fact that in the Brosh et al. study, they used the same buccal brackets (Victory, 3M-Unitek) for both sides: Buccal and lingual. The lack of the adaptation of the brackets to the lingual surface could justify the decrease of the necessary strength to debond them and the increase of the ARI score on the lingual side. In the present study, specific lingual 
brackets were used for the lingual side, ensuring better adaptation. In addition, Sung et al. obtained a statistically higher ARI score associated with extended gold alloy custom base lingual multibracket appliances compared with conventional limited resin custom base lingual multibracket appliances. However, no statistically significant differences were shown between the debonding forces of extended gold alloy custom base lingual multibracket appliances $(69.29 \pm 9.59 \mathrm{~N})$ and conventional limited resin custom base lingual multibracket appliances (60.83 $\pm 10.12 \mathrm{~N})$ [26]. However, resin mesh of lingual multibracket appliances obtained higher ARI scores compared with metallic custom mesh of lingual multibracket appliances [27]. Otherwise, the influence of polishing of cement remnants on the enamel surfaces has also been analyzed, and an increase of enamel roughness in both buccal [28] and lingual multibracket appliances was reported [9]; therefore, the polishing of cement remnants is still a challenge for clinicians [29]. Eichenberger et al. reported $0.20 \mu \mathrm{m}$ of enamel removed after cement polishing of the lingual multibracket appliance therapy [30], and Janiszewska-Olszowska et al. reported $13.70 \mu \mathrm{m}$ of enamel removed after cement polishing of the buccal multibracket appliance therapy with a tungsten carbide bur [8].

\section{Conclusions}

In conclusion, within the limitations of this study, lingual multibracket appliance therapy leads to less area and volume of remaining cement after multibracket appliance debonding and less area and volume of remaining cement after cement polishing compared with buccal multibracket appliance therapy. However, the area and volume of enamel removed after cement polishing were similar between both lingual and buccal multibracket appliance therapies.

Author Contributions: Conceptualization, A.B.M.; Formal analysis, A.C., and Á.Z.-M.; Investigation, A.C., J.A.P.-B. and C.G.-B.; Methodology, J.A.P.-B.; Project administration, Á.Z.-M.; Software, J.A.P.-B.; Supervision, A.A.M.; Writing—original draft, Á.Z.-M.; Writing—review \& editing, C.G.-B. and R.M.C.G. All authors have read and agreed to the published version of the manuscript.

Funding: This research received no external funding.

Institutional Review Board Statement: Not applicable.

Informed Consent Statement: Not applicable.

Data Availability Statement: Data available on request due to restrictions eg privacy or ethical.

Conflicts of Interest: The authors declare no conflict of interest.

\section{References}

1. Papageorgiou, S.N.; Gölz, L.; Jäger, A.; Eliades, T.; Bourauel, C. Lingual vs. labial fixed orthodontic appliances: Systematic review and meta-analysis of treatment effects. Eur. J. Oral Sci. 2016, 124, 105-118. [CrossRef]

2. Knösel, M.; Alvarez, R.V.; Blanck-Lubarsch, M.; Helms, H.J. Comparison of potential long-term costs for preventive dentistry treatment of post-orthodontic labial versus lingual enamel cavitations and esthetically relevant white-spot lesions: A simulation study with different scenarios. Head Face Med. 2019, 15, 22. [CrossRef]

3. Hu, H.; Feng, C.; Jiang, Z.; Wang, L.; Shrestha, S.; Yan, J.; Shu, Y.; Ge, L.; Lai, W.; Hua, F.; et al. Effectiveness of remineralizing agents in the prevention and reversal of orthodontically induced white spot lesions: A systematic review and network meta-analysis. Clin. Oral Investig. 2020, 24, 4153-4167. [CrossRef] [PubMed]

4. Botzenhart, U.U.; Henningsen, A.; Quaas, S.; Luthardt, R.G.; Proff, P.; Spassov, A.; Gedrange, T. 3D assisted morphological analysis of lingual upper central and lateral incisor surfaces. Biomed. Eng./Biomed. Tech. 2012, 57, 71-77. [CrossRef]

5. Brosh, T.; Strouthou, S.; Sarne, O. Effects of buccal versus lingual surfaces, enamel conditioning procedures and storage duration on brackets debonding characteristics. J. Dent. 2005, 33, 99-105. [CrossRef] [PubMed]

6. Hudson, A.P.; Grobler, S.R.; Harris, A.M. Orthodontic molar brackets: The effect of three different base designs on shear bond strength. Int. J. Biomed. Sci. 2011, 7, 27-34. [PubMed]

7. Hobson, R.S.; Rugg-Gunn, A.J.; Booth, T.A. Acid-etch patterns on the buccal surface of human permanent teeth. Arch. Oral Biol. 2002, 47, 407-412. [PubMed]

8. Mavreas, D.; Cuzin, J.F.; Boonen, G.; Vande Vannet, B. The effect of various adhesives, enamel etching, and base treatment on the failure frequency of customized lingual brackets: A randomized clinical trial. Eur. J. Orthod. 2018, 40, 249-253. [CrossRef] 
9. Janiszewska-Olszowska, J.; Tomkowski, R.; Tandecka, K.; Stepien, P.; Szatkiewicz, T.; Sporniak-Tutak, K.; Grocholewicz, K. Effect of orthodontic debonding and residual adhesive removal on 3D enamel microroughness. PeerJ 2016, 4, e2558. [CrossRef] [PubMed]

10. Garg, R.; Dixit, P.; Khosla, T.; Gupta, P.; Kalra, H.; Kumar, P. Enamel Surface Roughness after Debonding: A Comparative Study using Three Different Burs. J. Contemp. Dent. Pract. 2018, 19, 521-526. [PubMed]

11. Mati, M.; Amm, E.; Bouserhal, J.; Bassil-Nassif, N. Effects of buccal and lingual enamel sandblasting on shear bond strength of orthodontic brackets bonded with a self-etching primer. Int. Orthod. 2012, 10, 422-431. [CrossRef] [PubMed]

12. Medina-Sotomayor, P.; Pascual-Moscardó, A.; Camps, I. Relationship between resolution and accuracy of four intraoral scanners in complete-arch impressions. J. Clin. Exp. Dent. 2018, 10, e361-e366. [CrossRef] [PubMed]

13. Van der Veen, M.H.; Attin, R.; Schwestka-Polly, R.; Wiechmann, D. Caries outcomes after orthodontic treatment with fixed appliances: Do lingual brackets make a difference? Eur. J. Oral Sci. 2010, 118, 298-303. [CrossRef] [PubMed]

14. Lin, Y.C.; Lai, Y.L.; Chen, W.T.; Lee, S.Y. Kinetics of fluoride release from and reuptake by orthodontic cements. Am. J. Orthod. Dentofac. Orthop. 2008, 133, 427-434. [CrossRef]

15. Pham, D.; Bollu, P.; Chaudhry, K.; Subramani, K. Comparative evaluation of orthodontic bracket base shapes on shear bond strength and adhesive remnant index: An in vitro study. J. Clin. Exp. Dent. 2017, 9, e848-e854.

16. Tuncer, C.; Ulusoy, Ç. Tensile bond strength of lingual orthodontic brackets with adhesive systems. World J. Orthod. 2010, 11, 393-397.

17. Saraç, Y.Ş.; Külünk, T.; Elekdağ-Türk, S.; Saraç, D.; Türk, T. Effects of surface-conditioning methods on shear bond strength of brackets bonded to different all-ceramic materials. Eur. J. Orthod. 2011, 33, 667-672. [CrossRef]

18. Lopes, M.S.; Pereira, D.L.; de Oliveira Mota, C.C.B.; Amaral, M.M.; Zezell, D.M.; Gomes, A.S.L. The lingual enamel morphology and bracket shear bond strength influenced by Nd:YAG laser and aluminum oxide sandblasting preconditioning. Clin. Oral Investig. 2021, 25, 1151-1158. [CrossRef]

19. Hamdani, S.; Anita, G.; Sodawala, J.; Gandhi, S.; Ali, S.M. The effect of pre-etching with 37\% orthophosphoric acid on the shear bond strength of orthodontic brackets bonded using self-etching primer-adhesive system. Indian J. Dent. Res. 2016, $27,498-501$. [CrossRef]

20. Valletta, R.; Prisco, D.; De Santis, R.; Ambrosio, L.; Martina, R. Evaluation of the debonding strength of orthodontic brackets using three different bonding systems. Eur. J. Orthod. 2007, 29, 571-577.

21. Vinagre, A.R.; Messias, A.L.; Gomes, M.A.; Costa, A.L.; Ramos, J.C. Effect of time on shear bond strength of four orthodontic adhesive systems. Rev. Port. Estomatol. Med. Dent. Maxilofac. 2014, 55, 142-151. [CrossRef]

22. Cucu, M.; Driessen, C.H.; Ferreira, P.D. The influence of orthodontic bracket base diameter and mesh size on bond strength. $S$. Afr. Mella. J. 2002, 57, 16-20.

23. Sharma-Sayal, S.K.; Rossouw, P.E.; Kulkarni, G.V.; Titley, K.C. The influence of orthodontic bracket base design on shear bond strength. Am. J. Orthod. Dentofac. Orthop. 2003, 124, 74-82. [CrossRef]

24. Chumak, L.; Galil, K.A.; Way, D.C.; Johnson, L.N.; Hunter, W.S. An in vitro investigation of lingual bonding. Am. J. Orthod. Dentofac. Orthop. 1989, 95, 20-28. [CrossRef]

25. Ziebura, T.; Hohoff, A.; Flieger, S.; Stamm, T. Accidental debondings: Buccal vs fully individualized lingual multibracket appliances. Am. J. Orthod. Dentofac. Orthop. 2014, 145, 649-654. [CrossRef]

26. Sung, J.W.; Kwon, T.Y.; Kyung, H.M. Debonding forces of three different customized bases of a lingual bracket system. Korean J. Orthod. 2013, 43, 235-241. [CrossRef] [PubMed]

27. Arima, V.O.; Vedovello Filho, M.; Valdrighi, H.C.; Lucato, A.S.; Santamaria, M., Jr.; Vedovello, S.A.S. Debonding forces of different pads in a lingual bracket system. Dental Press J. Orthod. 2017, 22, 34-40. [CrossRef]

28. Erdur, E.A.; Akın, M.; Cime, L.; İleri, Z. Evaluation of Enamel Surface Roughness after Various Finishing Techniques for Debonding of Orthodontic Brackets. Turk. J. Orthod. 2016, 29, 1-5. [CrossRef] [PubMed]

29. Mandall, N.A.; Hickman, J.; Macfarlane, T.V.; Mattick, R.C.; Millett, D.T.; Worthington, H.V. Adhesives for fixed orthodontic brackets. Cochrane Database Syst. Rev. 2018, 4, CD002282. [CrossRef]

30. Eichenberger, M.; Iliadi, A.; Koletsi, D.; Eliades, G.; Verna, C.; Eliades, T. Enamel Surface Roughness after Lingual Bracket Debonding: An In Vitro Study. Materials 2019, 12, 4196. 